\title{
Temporomandibular Disorder in University Students of the Parque das Rosas Campus, Universidade Estácio de Sá That Practice Sports
}

\author{
Rosineli Paz Cabral1,2, Manuel Eduardo Moiolli-Rodrigues', \\ Flávia Lima Kleinsorgen Motta1, Francisco Carlos Kleinsorgen de Souza Motta1, \\ Juliana Rocha da Silva ${ }^{2}$, Larissa Malheiros ${ }^{1,2}$, Neide Martins', Leonardo Trepte1, \\ André Luiz G. Abrão1, Adalgisa Maiworm³ ${ }^{1}$, Luiz Carlos Oliveira1, \\ Raphael Lemgruber Cardoso1, Adriano Arnóbio3 ${ }^{3}$, Giuseppe Antonio Presta1,3, \\ Danúbia da Cunha de Sá Caputo ${ }^{3,4}$, Sebastião David Santos Filho5, \\ Éric Heleno F. F. Frederico3,6*, Mario Bernardo-Filho3, Severo de Paoli1,2,3

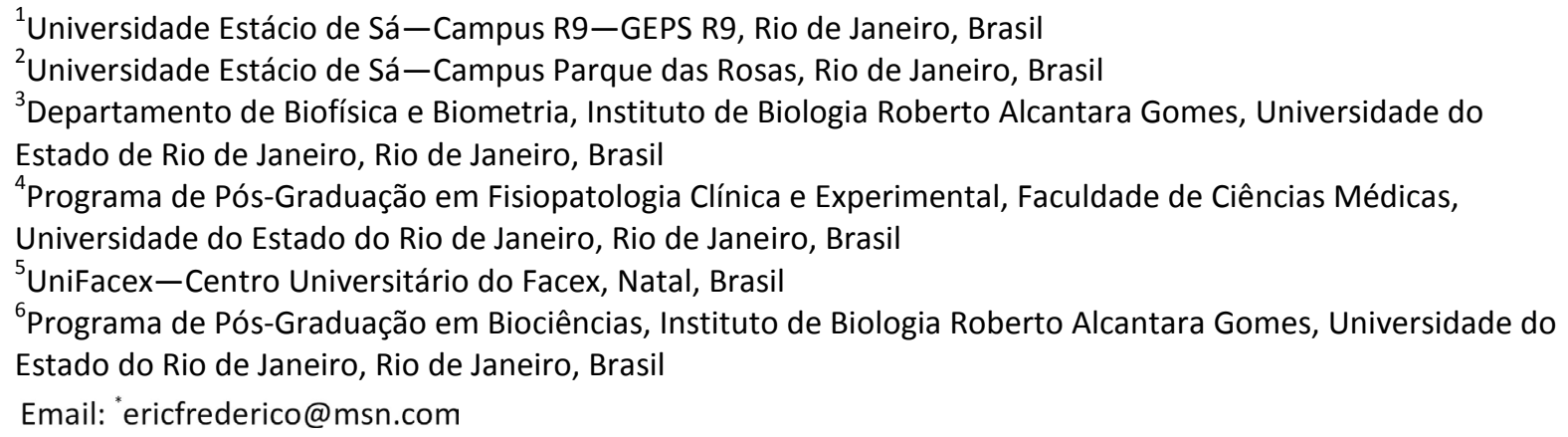

Received 1 September 2015; accepted 9 January 2016; published 12 January 2016

Copyright (C) 2016 by authors and Scientific Research Publishing Inc.

This work is licensed under the Creative Commons Attribution International License (CC BY).

http://creativecommons.org/licenses/by/4.0/

(c) $\underset{\mathrm{EY}}{\mathrm{B}}$ Open Access

\section{Abstract}

The stomatognathic system (SS) is a functional unit of the body that depends on the balance of several tissues. It consists of various structures, including the temporomandibular joint. Temporomandibular disorder (TMD) can occur due to alterations in the SS. The Fonseca Anamnestic Index (FAI) is a scale used to evaluate and to characterize the TMD Type: no DTM, mild, moderate and severe. The aim is to evaluate the prevalence of signs and symptoms related to TMD in university students of the Parque das Rosas Campus, Universidade Estácio de Sá that practice sports. This investigation was approved (CAAE number 325678413.9.0000.5284). Two hundred eighth

\footnotetext{
*Corresponding author.
}

How to cite this paper: Cabral, R.P., et al. (2016) Temporomandibular Disorder in University Students of the Parque das Rosas Campus, Universidade Estácio de Sá That Practice Sports. Health, 8, 18-23. 
students (110 male and 98 female, aged 19 - 35 years) accepted to be in this investigation. All the participants answered a General Questionnaire (GQ) and the FAI. The GQ had questions about the age, sex and the presence of TMD. The FAI was used. A statistical difference $(p>0.05)$ was not found about the presence of TMD. Among the female, an elevated number of the students with signal or symptoms related to the temporomandibular with statistic significance $(p<0.05)$ was observed. In the population without TMD, the prevalence of this disorder is higher between male than female. Considering the FAI, among the female students, there is a prevalence of the Mild Type. Considering the evaluation of the type of TMD among the male and female students no difference was found between male and female to the types mild and moderate, however, the prevalence of the severe Type is higher in female than in male with statistical significance. In conclusion, TMD is a relevant clinical condition with an important prevalence among the university students. Moreover, the type of the TMD could be considered due to prevalence of the Type Severe among the women.

\section{Keywords}

Temporomandibular Disorder, University Student, Fonseca Anamnestic Index, Prevalence

\section{Introduction}

The stomatognathic system is a functional unit of the body that depends on the balance of several tissues [1]. It consists of various structures, including the temporomandibular joint (TMJ) in association with muscles. Mandibular functions, as speech, chewing and swallowing are related to this complex system [2]. The temporomandibular disorder (TMD) can occur due to alterations in the stomatognathic system, which is characterized by several clinical abnormalities. Furthermore, closed anatomic regions, such as the facial and cervical muscles can have problem [3]-[5]. About 37.5\% of the adult population has some signs or symptoms related to the TMD [6]. Putting together the clinical features of the pathogenesis of the TMD, some of the main symptoms related to this disturbance are TMJ pain, headache, popping, ear pain, facial pain, functional limitation, neck pain, fatigue, mouth opening limitation, pain while chewing, tinnitus, pain in the jaw. Nevertheless, in some cases, the presence of TMD is asymptomatic [3] [7] [8]. Saito et al., [9] have reported a close relationship between body posture and TMD, however it is not possible to determine whether postural deviations are the cause or the result of this TMD. In addition, it is considered that the postural evaluation could be an important component in the overall approach to providing accurate prevention and treatment in the management of patients with TMD.

In sports, Oztürk et al., [10] have reported that the design of a diving regulator's mouthpiece increases the risk of TMD in scuba divers. Shirani et al., [11] have pointed out that the prevalence of facial injuries from combat sports professionals was significantly high, especially in kickboxing. In addition, Muhtaroğullari et al., [12] have described non-surgical treatment of sports-related temporomandibular joint disorders in basketball players and they consider that sports-related TMD injuries may result in complex problems such as pain, TMD sounds, limitation in maximal jaw movements and maximum opening of the mouth, difficulty in chewing.

The Fonseca Anamnestic Index (FAI) is a scale used to evaluate and to characterize the TMD signs and symptoms, by facilitating the collection of information in a short period of time, with low cost, with easy understanding and not have influence of the evaluator in the answer of the questions. The FAI would serve as a preliminary TMD screening tool. The use of FAI is easily used by either general practitioners or epidemiologists [13] [14].

Putting together these considerations, the aim of this investigation is to evaluate the prevalence of signs and symptoms related to TMD disorder in university students of the Parque das Rosas Campus, Universidade Estácio de Sá that practice sports.

\section{Material and Methods}

\subsection{Type of the Study and Ethics Approach}

This is a descriptive-correlational investigation that was approved by the Ethics Committee of the Universidade 
Estácio de Sá/UNESA/RJ (number 325678413.9.0000.5284).

\subsection{Individuals}

Among the university students of the Parque das Rosas Campus, Universidade Estácio de Sá, those that practice some modality of sports were invited to participate in this study. This invitation was due to the possibility of risk of TMD in some sports [10]-[12]. Two hundred eight students (110 male and 98 female, aged between 19 and 35 years) accepted to be in this investigation. They signed a term of free and informed consent [TFIC] to participate.

\subsection{Inclusion and Exclusion Criteria}

Inclusion criteria were individuals (i) University students of the of Universidade Estácio de Sá, (ii) both sexes, (iii) with age between 19 and 35 year old and that (iv) signed the TFIC. The exclusion criteria were students of other Universities, with age outside the range of 19 and 35 years old and that have not signed the TFIC.

\subsection{Methodology}

All the participants answered a General Questionnaire (GQ) and the Fonseca Anamnestic Index (FAI) between August 2014 and June 2015. A specific, comfortable and isolated room was used to the interviews.

The GQ had questions about the age, sex and the presence of TMD that were directly answered. How old are you? Which is your sex, male or female? Do you have temporomandibular disorder? Yes or No.

The FAI [14] was used to evaluate and to characterize the TMD signs and symptoms. It is also used to classify individuals according to TMD severity (mild, moderate, severe and no TMD). Two questions were added to the FAI (a) the previous diagnosis of the TMD and (b) about some treatment to the TMD. The possible answers were YES or NO.

The FAI [14] has ten questions and the possible answers are NO, SOMETIMES or YES. Questions about the (a) presence of pain in the TMJ, head and neck, (b) pain while chewing, and (c) functional habits, limitation of the movement of the TMJ, perception of malocclusion and (d) destress and emotions are in the FAI. Each type of answer has a value, where NO is 0, SOMETIMES 5 and YES 10 points. The total value (addition of value of each question) permit to classify the participants in (i) no TMD (0 - 15 points), (ii) mild TMD (20 - 40 points), (iii) moderate TMD (45 - 65 points) and (iv) severe TMD (70 to 100 values).

\subsection{Statistical Analysis}

The Chi-square was performed for the statistical analysis of the results with BioEstat 5.3 (Instituto Mamiraua, Pará, Brasil). A p-value of less than 0.05 was considered statistical significance.

\section{Results}

Considering the GQ and the total number of questionnaires, 208 in Table 1, it is possible to verify the prevalence of TMD of the evaluated individuals that practice sports. It is important to consider that a statistical difference ( $\mathrm{p}>0.05$ ) was not found about the presence of TMD among the university students of the Parque das Rosas Campus, Universidade Estácio de Sá that practice sports.

In Table 2 is shown, among the female, the number of the students that practice sports with signal or symptoms related to the TMD with statistic significance $(\mathrm{p}<0.05)$. However, in this studied population, in the male students, there is no prevalence of TMD among the university students of the Parque das Rosas Campus, Universidade Estácio de Sá that practice sports.

In Table 3 is shown that, among the participants with TMD, there is no statistic difference between male and female ( $\mathrm{p}>0.05$ ). However, in the studied population without TMD, the prevalence of this disorder is higher between male than female that are university students of the Parque das Rosas Campus, Universidade Estácio de Sá that practice sports and this is statistically significant $(\mathrm{p}<0.05)$.

In Table 4 is shown the prevalence of the type of TMD in female and male student following the Fonseca Anamnestic Index. It is shown that, among the female university students of the Parque das Rosas Campus, Universidade Estácio de Sá that practice sports, there a prevalence of the Mild Type, that is significant $(\mathrm{p}<0.05)$, in comparison with the other types of TMD (moderate and severe) and with no TMD. Among the male university 
Table 1. Prevalence of TMD among the university students.

\begin{tabular}{cccc}
\hline Number of Participants & With TMD & Without TMD & p \\
\hline 208 & $120(57.7 \%)$ & $88(42.3 \%)$ & 0.1236 \\
\hline
\end{tabular}

Table 2. Prevalence of TMD in male and female students that practice sports.

\begin{tabular}{cccc}
\hline Gender & With TMD & Without TMD & p \\
\hline Female & $67(68.4 \%)$ & $31(31.6 \%)$ & 0.0002 \\
Male & $53(48.2 \%)$ & $57(51.8 \%)$ & 0.7188 \\
\hline
\end{tabular}

Table 3. Prevalence of TMD in male and female.

\begin{tabular}{cccc}
\hline & Female & Male & p \\
\hline With TMD & $67(55.8 \%)$ & $53(44.2 \%)$ & 0.2460 \\
Without TMD & $31(35.2 \%)$ & $57(64.8 \%)$ & 0.0031 \\
\hline
\end{tabular}

Table 4. Type of DTM in female and male student following the Fonseca Anamnestic Index.

\begin{tabular}{cccccc}
\hline Gender & No TMD & Mild TMD & Moderate TMD & Severe TMD & p \\
\hline Female & $31(31.6 \%)$ & $45(45.9 \%)$ & $15(15.3 \%)$ & $7(7.2 \%)$ & $<0.0001$ \\
Male & $57(51.8 \%)$ & $38(34.5 \%)$ & $12(11.0 \%)$ & $3(2.7 \%)$ & $<0.0001$ \\
\hline
\end{tabular}

students, there a prevalence of the no TMD, that is significant $\mathrm{p}<0.05$ ), in comparison with the types of TMD (mild, moderate and severe).

Considering the evaluation of the type of TMD among the male and female university students of the Parque das Rosas Campus, Universidade Estácio de Sá that practice sports, the findings are presented in Table 5. No difference was found between male and female to the types mild and moderate, however, the prevalence of the severe Type is higher in female than in male with statistical significance $(\mathrm{p}<0.05)$.

\section{Discussion}

The evaluation of the prevalence of signs and symptoms related to temporoamandibular disorder in university students is highly desirable due to the various clinical problems associated with the TMD [3] [7] [8]. In the group of participants that are university students of the Parque das Rosas Campus, Universidade Estácio de Sá that practice sports, and it was shown an important number of participants with TMD (Table 1). In general, these findings are in agreement with (i) Conti et al., [4] that studied the prevalence and etiology of signs and symptoms of TMD in high school and university students, (ii) Oliveira et al., [15] that have evaluated signs and symptoms of TMD in Brazilian college students, (iii) Tanboga et al. [16] have found that 61\% young athletes have, at least, a signal related to the TMD and (iv) Zwiri et al., [17], that studied the prevalence of TMD among North Saudi University students.

Considering the prevalence of TMD in male and female students that practice sports, it was shown in Table 2, among the female, an elevated number of the students that practice sports with signal or symptoms related to the temporomandibular with statistic significance $(\mathrm{p}<0.05)$. Vedolin et al., [18] have already reported a high prevalence of TMD among the women. Moreover, these authors consider that the high prevalence of TMD among the women would be related to physiologic characteristics of the female, as hormonal fluctuations, muscular structure and low limiar to the pain. Pedroni et al., [19] have also described a high prevalence of TMD in women. Feteih, [20], Pollard and Fernandez, [21] and Yuill and Howitt, [22] also agree with these considerations.

The analysis of the prevalence of the type of TMD in female and male student following the Fonseca Anamnestic Index (Table 4), it was shown that, among the female university students of the Parque das Rosas Campus, Universidade Estácio de Sá that practice sports, there a significant prevalence of the Mild Type in compari- 
Table 5. Type of DTM in female and male.

\begin{tabular}{cccc}
\hline Type of TMD & Female & Male & $\mathrm{p}$ \\
\hline Mild & $45(54.2 \%)$ & $38(45.8 \%)$ & 0.4009 \\
Moderate & $15(53.6 \%)$ & $12(46.4 \%)$ & 0.4715 \\
Severe & $7(70.0 \%)$ & $3(30.0 \%)$ & $<0.0001$ \\
\hline
\end{tabular}

son with the other types of TMD (moderate and severe) and with no TMD. Among the male university students, there is a significant prevalence of the no TMD in comparison with the types of TMD (mild, moderate and severe) (Table 5). Considering the evaluation of the type of TMD among the male and female university students of the Parque das Rosas Campus, Universidade Estácio de Sá that practice sports, no difference was found between male and female to the types mild and moderate, however, the prevalence $(\mathrm{p}<0.05)$ of the severe type is higher in female than in male. Tanboga et al. [16] have found a prevalence of $22.5 \%$ of the Type Moderate, while Conti et al. [4] have reported $16.08 \%$ among the individuals. The findings presented in Table 4 shown values that are similar to these, as $15.3 \%$ to female and $11.0 \%$ to male.

Considering the type of TMD, Severe, in Table 5 there is an important finding that brings a worried. This type of DTM is higher in female that in male. This fact could be related to physiologic characteristics of the female (Pedroni et al., [19], Feteih, [20], Pollard and Fernandez, [21] and Yuill and Howitt, [22]) and they must be considerated in the competitions.

As recommendation, considering that, in some cases, the presence of TMD is asymptomatic, the findings described in this investigation will be relevant to try to prevent the presence of TMD among university students that practice sports.

\section{Conclusion}

In conclusion, TMD is a relevant clinical condition with an important prevalence among the university students. Moreover, the type of the TMD could be considered due to prevalence of the Type Severe among the women.

\section{Acknowledgements}

Thanks for the support by Universidade Estácio de Sá, Universidade do Estado do Rio de Janeiro and Centro Universitário do Facex.

\section{References}

[1] Alves, R.L.B.R., Silva, P.F.S., Veiga, P.H.A. and Daher, C.M. (2010) A eficácia dos recursos fisioterapêuticos no ganho da amplitude bucal em pacientes com disfunções crânio mandibulares. Odontologia, UNESP, Araraquara (SP), 39, 55-61.

[2] Rockland, A., Teixeira, A.V.A., Vieira da Silva, J., Lima, S.A.A. and Oliveira, AV. (2010) Influência da disfunção temporomandibular muscular nas alterações da qualidade vocal. Revista Portuguesa de Estomatologia, Medicina Dentária e Cirurgia Maxilofacial, 51, 41-47. http://dx.doi.org/10.1016/S1646-2890(10)70084-4

[3] Carrara, S.V., Conti, P.C.R. and Barbosa, J.S. (2010) Termo do $1^{\circ}$ Consenso em Disfunção Temporomandibular e Dor Orofacial. Dental Press Journal of Orthodontics, 15, 114-120. http://dx.doi.org/10.1590/S2176-94512010000300014

[4] Conti, P.C.R., Ferreira, P.M., Pegoraro, L.F., Conti, J.V. and Salvador, M.C. (1996) A Cross-Sectional Study of Prevalence and Etiology of Signs and Symptoms of Temporomandibular Disorders in High School and University Students. Journal of Orofacial Pain, 10, 254-262.

[5] Barbosa, I.A.M.S., Silva, P.E. and Silva, K.A.F. (2010) Tratamento das disfunções da articulação temporomandibular por meio da técnica de dígito pressão. Revista Eletrônica Saúde CESUC, 1.

[6] Gonçalves, D.A., Speciali, J.G., Jales, L.C., Camparis, C.M. and Bigal, M.E. (2009) Temporomandibular Symptoms, Migraine and Chronic Daily Headaches in the Population. Neurology, 73, 645-646. http://dx.doi.org/10.1212/WNL.0b013e3181b389c2

[7] Fernandez, C.E., Amiri, A., Jaime, J. and Delaney, P. (2009) The Relationship of Whiplash Injury and Temporomandibular Disorders: A Narrative Literature Review. Journal of Chiropractic Medicine, 8, 171-186. http://dx.doi.org/10.1016/j.jcm.2009.07.006 
[8] Anderson, G.C., John, M.T., Ohrbach, R., Nixdorf, D.R., Schiffman, E.L., Truelove, E.S. and List, T. (2011) Influence of Headache Frequency on Clinical Signs and Symptoms of TMD in Subjects with Temple Headache and TMD Pain. Pain, 152, 765-71. http://dx.doi.org/10.1016/j.pain.2010.11.007

[9] Saito, E.T., Akashi, P.M. and Sacco Ide, C. (2009) Global Body Posture Evaluation in Patients with Temporomandibular Joint Disorder. Clinics (Sao Paulo), 64, 35-39. http://dx.doi.org/10.1590/S1807-59322009000100007

[10] Oztürk, O., Tek, M. and Seven, H. (2012) Temporomandibular Disorders in Scuba Divers—An Increased Risk during Diving Certification Training. Journal of Craniofacial Surgery, 23, 1825-1829. http://dx.doi.org/10.1097/SCS.0b013e3182710577

[11] Shirani, G., Kalantar Motamedi, M.H., Ashuri, A. and Eshkevari, P.S. (2010) Prevalence and Patterns of Combat Sport Related Maxillofacial Injuries. Journal of Emergencies, Trauma and Shock, 3, 314-317. http://dx.doi.org/10.4103/0974-2700.70744

[12] Muhtaroğullari, M., Demiralp, B. and Ertan, A. (2004) Non-Surgical Treatment of Sports-Related Temporomandibular Joint Disorders in Basketball Players. Dental Traumatology, 20, 338-343. http://dx.doi.org/10.1111/j.1600-9657.2004.00267.x

[13] Habib, S.R., Al Rifaiy, M.Q., Awan, K.H., Alsaif, A., Alshalan, A. and Altokais, Y. (2015) Prevalence and Severity of Temporomandibular Disorders among University Students in Riyadh. The Saudi Dental Journal, 27, 125-130. http://dx.doi.org/10.1016/j.sdentj.2014.11.009

[14] Campos, J.A., Carrascosa, A.C., Bonafé, F.S. and Maroco, J. (2014) Severity of Temporomandibular Disorders in Women: Validity and Reliability of the Fonseca Anamnestic Index. Brazilian Oral Research, 28, 16-21. http://dx.doi.org/10.1590/S1806-83242013005000026

[15] Oliveira, A., Dias, E., Contato, R. and Berzin, F. (2006) Prevalence Study of Signs and Symptoms of Temporomandibular Disorder in Brazilian College Students. Brazilian Oral Research, 20, 3-7. http://dx.doi.org/10.1590/S1806-83242006000100002

[16] Tanboga, I., Durhan, M.A., Durmus, B. and Marks, L.A. (2014) Temporomandibular Disorders in Young People with an Intellectual Disability: Prevalence of Signs and Symptoms. European Journal of Paediatric Dentistry, 15, 349-354.

[17] Zwiri, A.M. and Al-Omiri, M.K. (2015) Prevalence of Temporomandibular Joint Disorder among North Saudi University Students. Cranio, 2151090315Y0000000007. http://dx.doi.org/10.1080/08869634.2015.1097334

[18] Vedolin, G.M., Lobato, V.V., Conti, P.C. and Lauris, J.R. (2009) The Impact of Stress and Anxiety on the Pressure Pain Threshold of Myofascial Pain Patients. Journal of Oral Rehabilitation, 36, 313-321. http://dx.doi.org/10.1111/j.1365-2842.2008.01932.x

[19] Pedroni, C.R., Oliveira, A.S. and Guaratini, M.I. (2003) Prevalence Study of Signs and Symptoms of Temporomandibular Disorders in University Students. Journal of Oral Rehabilitation, 30, 283-289. http://dx.doi.org/10.1046/j.1365-2842.2003.01010.x

[20] Feteih, R.M. (2006) Signs and Symptoms of Temporomandibular Disorders and Oral Parafunctions in Urban Saudi Arabian Adolescents: A Research Report. Head and Face Medicne, 2, 25. http://dx.doi.org/10.1186/1746-160X-2-25

[21] Pollard, H. and Fernandez, M. (2004) Spinal Musculoskeletal Injuries Associated with Swimming: A Discussion of Technique. Australian Chiropractors and Osteopaths, 12, 72-80.

[22] Yuill, E. and Howitt, S.D. (2009) Temporomandibular Joint: Conservative Care of TMJ Dysfunction in a Competitive Swimmer. The Journal of the Canadian Chiropractic Association, 53, 165-172. 